Article

\title{
Evaluation of a Recombinant Mouse X Pig Chimeric Anti-Porcine DEC205 Antibody Fused with Structural and Nonstructural Peptides of PRRS Virus
}

\author{
Lorena Bustamante-Córdova $\mathbb{D}$, Mónica Reséndiz-Sandoval and Jesús Hernández * $\mathbb{D}$ \\ Laboratorio de Inmunología, Centro de Investigación en Alimentación y Desarrollo, A.C., Hermosillo 83304, \\ Sonora, Mexico; lorebcw@gmail.com (L.B.-C.); mresendiz@ciad.mx (M.R.-S.) \\ * Correspondence: jhdez@ciad.mx; Tel.: +52-6628-000-425
}

Received: 15 May 2019; Accepted: 21 May 2019; Published: 23 May 2019

\begin{abstract}
Activation of the immune system using antigen targeting to the dendritic cell receptor DEC205 presents great potential in the field of vaccination. The objective of this work was to evaluate the immunogenicity and protectiveness of a recombinant mouse $x$ pig chimeric antibody fused with peptides of structural and nonstructural proteins of porcine respiratory and reproductive syndrome virus (PRRSV) directed to DEC205 ${ }^{+}$cells. Priming and booster immunizations were performed three weeks apart and administered intradermally in the neck area. All pigs were challenged with PRRSV two weeks after the booster immunization. Immunogenicity was evaluated by assessing the presence of antibodies anti-PRRSV, the response of IFN- $\gamma$-producing $\mathrm{CD}^{+}$cells, and the proliferation of cells. Protection was determined by assessing the viral load in the blood, lungs, and tonsils using qRT-PCR. The results showed that the vaccine exhibited immunogenicity but conferred limited protection. The vaccine group had a lower viral load in the tonsils and a significantly higher production of antibodies anti-PRRSV than the control group $(p<0.05)$; the vaccine group also produced more $\mathrm{CD} 4^{+} \mathrm{IFN}-\gamma^{+}$cells in response to peptides from the $\mathrm{M}$ and $\mathrm{Nsp} 2$ proteins. In conclusion, this antigenized recombinant mouse $\mathrm{x}$ pig chimeric antibody had immunogenic properties that could be enhanced to improve the level of protection and vaccine efficiency.
\end{abstract}

Keywords: antigen targeting; DEC205; PRRSV; recombinant antibodies; chimeric antibody; dendritic cells

\section{Introduction}

Vaccination has been established as the most effective tool for the prevention, control, and eradication of infectious diseases; for this reason, improved vaccines are continuously pursued [1]. The targeting of antigens to dendritic cells (DCs) has been evaluated as a strategy to increase the effectiveness of vaccines. It has been reported that the targeting of C-type lectin receptors (CLRs) in mice and monkeys, even with low concentrations of antigen, is capable of generating a cellular immune response [2]. The targeting of the DEC205 receptor, a member of the family of CLRs, has been evaluated in vivo using anti-DEC205 antibodies conjugated with different antigens, such as ovalbumin, to induce antigen-specific $\mathrm{CD} 4^{+}$and $\mathrm{CD} 8^{+} \mathrm{T}$ lymphocyte responses in mice [3].

In murine models, it has been observed that targeting of the DEC205 receptor results in increases in the efficiency of antigen presentation [4], the stimulation of lymphocytes, and the production of IFN- $\gamma$ [5]. In birds, early and increased production of antibodies was found by targeting antigens from an avian influenza virus strain (H5N2) to the DEC205 receptor [6]. In cattle, a DNA vaccine was used to induce the production in situ of a single chain variable fragment $(\mathrm{scFv})$ directed against the DEC205 receptor, and the $\mathrm{scFv}$ was fused to the MSP1a antigen of the tick Anaplasma marginale [7]. This approach 
was successful in inducing a significant response by IFN- $\gamma$-producing CD4 ${ }^{+}$cells, the proliferation of $\mathrm{CD}^{+} \mathrm{T}$ cells, and increased antibody production, thus showing its immunogenicity.

Recently, the efficiency of targeting the DC-SIGN, Langerin and DEC205 porcine receptors was evaluated using structural proteins of porcine respiratory and reproductive virus (PRRSV) administered intramuscularly [8]. The use of a single chain fragment variable-fragment crystallizable region $(\mathrm{scFv}-\mathrm{Fc})$ (mouse x pig) induced a modest but nonsignificant increase in the production of total PRRSV antibodies in the vaccine group targeting DEC205 compared to that in the unvaccinated control group, with no effect on the production in the other target groups (DC-SIGN and Langerin). However, the frequency of IFN- $\gamma$-producing CD4 ${ }^{+}$cells was unaltered in the vaccine group targeting DEC205. Ultimately, no decrease in viremia was found, proving a lack of protection. The proteins used in this work included glycoprotein (GP) GP3, GP4, GP5, and the matrix (M) protein. The last two are the major envelope proteins, and these proteins are also considered to be among the most immunogenic proteins and are capable of inducing the production of neutralizing antibodies, especially when used together [9]. Other B cell epitopes have also been found in nonstructural proteins (Nsps), especially Nsp2 [10,11]. Although the humoral response is important in PRRSV infection, cellular mechanisms also contribute to the control of the virus [12]; thus, the stimulation of T cells is a key factor for vaccine effectiveness. Accordingly, other reports have identified several Nsps as having $\mathrm{T}$ cell epitopes that have the potential to induce IFN $\gamma$ production [13-15]. To prove the value of Nsps in vaccination, our working group produced a recombinant adenovirus that expressed several peptides from structural proteins and Nsps of PRRSV containing $\mathrm{T}$ cell epitopes, and this approach resulted in partial protection in challenged pigs [16]. The mentioned reports raise the possibility of using antigenized recombinant antibodies directed against pig DEC205 to enhance the effectiveness of the immune response and suggest that this approach has potential as a vaccination tool using B and T cell epitopes from PRRSV proteins. As a result, we designed a recombinant chimeric mouse $x$ pig antibody to direct structural and nonstructural peptides of PRRSV to the DEC205 receptor. Here, we evaluated the immunogenicity of the recombinant mouse $x$ pig chimeric antibody and its ability to induce protective immunity against PRRSV in immunized and challenged pigs.

\section{Materials and Methods}

\subsection{Animals}

Six 5-week-old pigs from a PRRSV-free farm were used. Their negative status was confirmed by qRT-PCR and ELISA. The pigs were housed in the facilities of the Centro de Investigación en Alimentación y Desarrollo, A.C. (CIAD, A.C.) with ad libitum access to food and water. Weight gain was monitored weekly throughout the experiment, and temperature changes were monitored during the first week after challenge. The animals were euthanized three weeks after challenge according to the protocols established in the Mexican Official Norm Nom-033-ZOO-1995 for the humane slaughter of domestic animals. The study was approved by the Ethics Committee of CIAD, A.C. (CE/021-B/2014).

\subsection{Virus Strains and Cell Lines Used}

MA104 derived monkey kidney MARC-145 cells were used for the propagation of PRRSV (strain National Veterinary Services Laboratory (NVSL) 97-7895) and were grown in Dulbecco's modified Eagle medium (DMEM; Gibco) with 10\% heat-inactivated fetal bovine serum (FBS; Equinotech) and antibiotics (100 IU penicillin $\mathrm{mL}^{-1}$ and $100 \mu \mathrm{g}$ streptomycin $\mathrm{mL}^{-1}$ (Sigma)). After the typical cytopathic effect was observed, cells were collected and lysed by freeze-thaw cycles and centrifuged at $650 \times g$ at $4{ }^{\circ} \mathrm{C}$ for $20 \mathrm{~min}$. Finally, the supernatant was separated, titrated, and stored at $-80^{\circ} \mathrm{C}$ until further use.

\subsection{Production of a Recombinant Mouse X Pig Chimeric Antibody}

Previously, in our laboratory, a mouse monoclonal antibody (mAb ZH9F7) was produced with classic hybridoma technology using a recombinant protein for the extracellular domains of the DEC205 
receptor (GenBank Accession No. GQ420669), as reported by our research group [17]. To construct our chimeric mouse $x$ pig antibody, the mouse Fc domain of the mAb ZH9F7 was replaced with that of a porcine $\mathrm{IgG}_{3}$, while the variable light and heavy chains from the original $\mathrm{mAb} \mathrm{ZH} 9 \mathrm{~F} 7$ remained. For the antigenized portion of the chimeric antibody, 12 peptides corresponding to structural and nonstructural proteins of PRRSV were selected from a previous work [16]. The selected peptides as well as their amino acid sequence and genotype (gen) are as follows: nsp2-SV (SLYKLLLEV gen I) [13]; nsp5-IV (ILNEVLPAV gen I) [13]; nsp9-KR (KEEIALSAQIIQACDIR gen II) [15]; nsp10-CL (CPGKNSFLDEAAYCNHL gen II) [15]; Gp5-SL (SHLQLIYNL gen II) [13]; Gp5-CR (CAFAAFVCFVIR gen I) [13]; Gp5-LC (LAALICFVIRLAKNC gen II) [13]; Gp5-KK (KGRLYRWRSPVIVEK gen II) [13]; Gp5-TP (TPLTRVSAEQWGRP gen II) [10]; M-CS (CNDSTAPQKVLLAFS gen II) [14]; M-AL (ALKVSRGRLLGLLHL gen II) [14]; and M-KK (KFITSRCRLCLLGRK gen II) [14]. The coding sequence for the PRRSV peptides was positioned at the carboxy-end of the Fc portion of the chimeric antibody, and each individual PRRSV peptide was separated from the others with two lysine residues (KK). The whole construct for the recombinant mouse $\mathrm{x}$ pig chimeric antigenized antibody, named $\mathrm{rAb}$ ZH9F7+A1 (Figure 1), was optimized (GenScript) for expression in a eukaryotic system and then cloned into the vector pcDNA 3.1(-) (Invitrogen). Finally, the mammalian cell line Expi293f was transiently transfected to express rAb ZH9F7+A1, following the manufacturer's protocol (Thermo-Fisher Scientific). The supernatant was collected at three days posttransfection, and the antibody was purified by affinity chromatography using HiTrap Protein A HP 1 mL columns (Sigma-Aldrich).

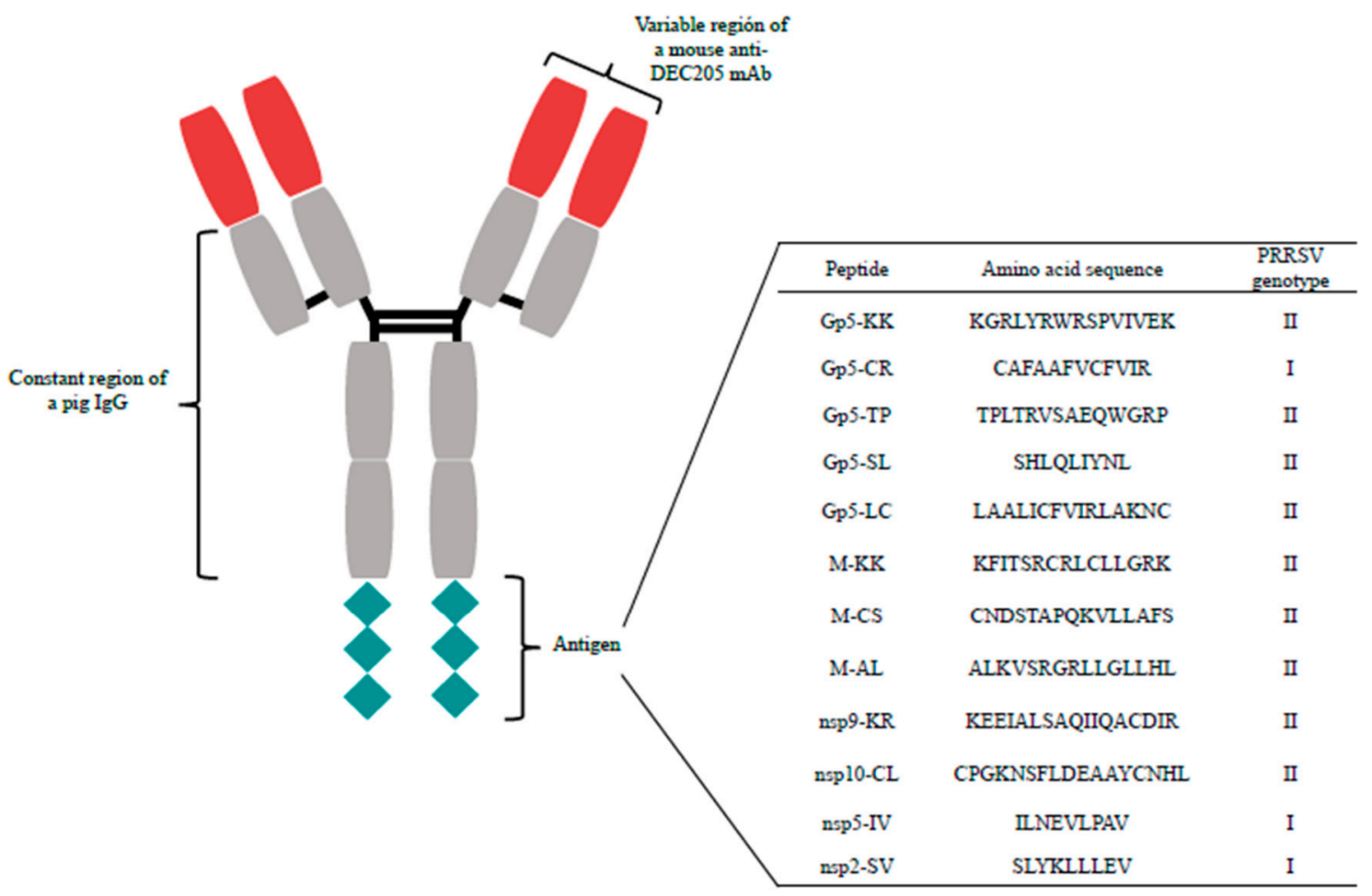

Figure 1. Graphic representation of the recombinant antigenized chimeric mouse $x$ pig antibody utilized. In blue: variable region of a mouse anti-DEC205 monoclonal antibody. In gray: constant region of a pig IgG. The antigenized part consists of a chimeric protein based on selected immunogenic peptides from PRRSV (red).

\subsection{Pig Immunization and Virus Challenge}

The immunization protocol included two groups: (a) the control group $(n=3)$, which was administered $200 \mu \mathrm{L}$ of sterile phosphate-buffered saline (1X PBS), and (b) the vaccine group $(n=3)$, which was immunized with $150 \mu \mathrm{g}$ of a chimeric mouse $\mathrm{x}$ pig recombinant antibody. This chimeric $\mathrm{rAb}$ was antigenized with a chimeric protein consisting of peptides from structural and nonstructural 
proteins of PRRSV (Figure 1). The immunizations in both groups included $100 \mu \mathrm{g}$ of adjuvant poly I:C (Polyinosine-Polycytidylic acid, Branched, Sigma-Aldrich). All immunizations were performed intradermally near the neck area. Three weeks after the first immunization, booster doses were administered to both groups in the same manner. Two weeks after the booster immunization, all pigs were challenged with $2 \times 10^{5}$ median tissue culture infectious dose (TCID 50 ) of PRRSV intranasally and euthanized three weeks after challenge.

\subsection{Isolation of PBMCs}

Peripheral blood mononuclear cells (PBMCs) were separated from whole blood in the anticoagulant EDTA using Ficoll-Hypaque (GE Healthcare Life Sciences) following the manufacturer's protocol. After gradient separation, the cells were washed with RPMI-1640 medium (Sigma-Aldrich) supplemented with antibiotics and resuspended in medium containing 10\% FBS.

\subsection{Intracellular IFN $\gamma$ Detection by Flow Cytometry}

Two weeks after challenge, the presence of IFN $\gamma$-producing $\mathrm{CD}^{+}$cells in the PBMC population was evaluated by flow cytometry to assess the Thelper lymphocytes 1 (Th1) response to different stimuli. Using 48-well plates, $1 \times 10^{6}$ PBMCs were stimulated for $24 \mathrm{~h}$ with $10 \mu \mathrm{g} / \mathrm{mL}$ individual peptides, a multiplicity of infection (MOI) of 0.1 of virus or $20 \mu \mathrm{g} / \mathrm{mL}$ phytohemagglutinin (PHA) as a positive control; unstimulated control wells were included for each pig. The cells were cultured in complete medium (RPMI-1640 medium supplemented with antibiotics, 10\% FBS, and $\beta$-mercaptoethanol). A protein transport inhibitor cocktail (eBioscience) was added to each individual well $16 \mathrm{~h}$ before harvest, as directed by the manufacturer's instructions. Then, the cells were harvested and extracellular labeling was performed with an anti-CD4 antibody conjugated with fluorescein isothiocyanate (FITC) (Southern Biotech). Afterwards, the cells were fixed and permeabilized with a Leucoperm kit (BioRad) following the maker's instructions for intracellular labeling with an anti-pig IFN $\gamma$ antibody conjugated with phycoerythrin (PE) (BD Biosciences). The stimulated cells were acquired and analyzed on a FACS CANTO II ${ }^{\mathrm{TM}}$ flow cytometer (BD Biosciences, Franklin Lakes, New Jersey, United States) using FACSDiva software.

\subsection{CFSE Proliferation Assay}

Three weeks after challenge, a proliferation assay was performed using carboxyfluorescein succinimidyl ester (CFSE) staining (BioLegend). The protocol used was a modified version of a previously reported protocol [18]. Briefly, isolated PBMCs were washed with sterile 1X PBS to remove FBS and resuspended in $1 \mathrm{~mL}$ of $5 \mu \mathrm{M}$ CFSE. The cell suspension was incubated for $15 \mathrm{~min}$ with gently mixing every $5 \mathrm{~min}$ to promote even staining. Next, $1 \mathrm{~mL}$ of FBS was added and incubated for an additional minute. Finally, the cells were washed with $10 \mathrm{~mL}$ of RPMI-1640 to remove any leftover CFSE and resuspended in complete cell culture medium. Using 48-well plates, $1 \times 10^{6}$ stained cells were stimulated in individual wells with $10 \mu \mathrm{g} / \mathrm{mL}$ individual peptides, an MOI of 0.1 of virus or $10 \mu \mathrm{g} / \mathrm{mL}$ PHA; unstimulated stained and unstained cells were also created for each pig as controls. After four days of incubation, the cells were collected and analyzed using a FACS CANTO II ${ }^{\mathrm{TM}}$ flow cytometer (BD Biosciences) and FACSDiva software (BD Biosciences, Franklin Lakes, New Jersey, United States).

\subsection{ELISA to Detect Specific Anti-PRRSV Antibodies}

Serum was collected from all pigs at the beginning of the experiment (Day 0 ) and on the booster day (Day 21), challenge day (Day 35), and the last day of the experiment (Day 56) to be analyzed for the presence of specific antibodies using a previously established ELISA protocol [16]. Briefly, 96-well plates (Corning) were coated with PRRSV $\left(10^{5} \mathrm{TCID}_{50}\right)$ diluted 1:100 using Carbonate Buffer $\mathrm{pH} 9.6$ overnight at $4{ }^{\circ} \mathrm{C}$. The plates were washed with phosphate-buffered saline and Tween (PBST) (PBS $1 \mathrm{X}$ with $0.05 \%$ Tween 20 ; Sigma-Aldrich), blocked with $300 \mu \mathrm{L}$ of blocking buffer (PBST $+5 \%$ fish gelatin; 
Sigma-Aldrich) per well, and incubated for $1 \mathrm{~h}$ at room temperature. After three washes with PBST, $100 \mu \mathrm{L}$ of each serum sample, at a 1:50 dilution, was added and incubated for $1 \mathrm{~h}$ at room temperature. Following three more washes, $100 \mu \mathrm{L}$ of anti-pig IgG detection antibody conjugated with horseradish peroxidase HRP (1:10,000 dilution) (Southern Biotech Associates, Inc.) was added to each well and incubated at room temperature for $1 \mathrm{~h}$, and the plates were then washed three times. Finally, $50 \mu \mathrm{L}$ of TMB substrate (Sigma-Aldrich) was added and incubated for $30 \mathrm{~min}$; the plates were then read at $450 \mathrm{~nm}$ using a BioRad 680 model microplate reader (Hercules, California, United States). In addition, to confirm the seroconversion of the challenged pigs, serum samples were evaluated with a commercial ELISA kit (Herdchek PPRS Antibody Test Kit, IDEXX Laboratories) following the manufacturer's protocol. In this case, samples were considered positive if the serum to positive $(\mathrm{S} / \mathrm{P})$ values $\geq 0.4$.

\subsection{PRRSV Detection by $q R T-P C R$ in the Serum, Tonsils, and Lungs}

To evaluate viremia in pigs, serum samples were collected at the time of challenge and three weeks postchallenge. Additionally, the presence of PRRSV in the tonsils and lungs at the time of euthanasia was determined. Tissue samples were collected and stored at $-20^{\circ} \mathrm{C}$ until processed. RNA extraction was performed with tissue samples using the RNeasy Mini Kit (QIAGEN) and with serum using the QIAamp Viral RNA Mini Kit (QIAGEN). SYBR®Green One-Step Real-Time RT-PCR Master Mix (Thermo-Fisher Scientific) was utilized for amplification under the following conditions: $48^{\circ} \mathrm{C}$ for $30 \mathrm{~min}, 95^{\circ} \mathrm{C}$ for $10 \mathrm{~min}$, and then 38 cycles of $10 \mathrm{~s}$ at $45^{\circ} \mathrm{C}$ and $30 \mathrm{~s}$ at $60^{\circ} \mathrm{C}$ in the StepOne ${ }^{\mathrm{TM}}$ Real-Time PCR System (Applied Biosystems, Foster City, California, United States). The primers used to amplify a 198 bp ORF6-7 fragment for genotype 2 PRRSV have been previously reported [19].

\subsection{Microscopic Pathological Evaluation}

Samples of the lungs of all infected pigs were stored in a buffered formaldehyde solution and later evaluated by a pathologist at the Laboratorio de la Asociación de Poricultores (Navojoa, Sonora, México). The lung lesion score assigned to each sample was based on the degree of interstitial pneumonia found according to the following scoring system: 0 -no significant lesions, 1 -mildly significant lesions, 2-moderately significant lesions, and 3-severely significant lesions, according to the pathologist's expertise.

\subsection{Statistical Analyses}

GraphPad Prism v6.0 software (San Diego, California, United States) was used to evaluate significant differences between the control and vaccine groups. Two-way ANOVA and Bonferroni multiple comparisons tests were performed for ELISA and viremia analyses. For all other data analyses, Student's $t$-tests were applied. A $p \leq 0.05$ was considered statistically significant.

\section{Results}

\subsection{Clinical Signs}

At the beginning of the experiment, the rectal temperature of the pigs in the control group was $39.7 \pm 0.3$, while the pigs in the vaccine group had a rectal temperature of $39 \pm 0.6{ }^{\circ} \mathrm{C}$, which was considered normal for swine. All pigs presented a fever $\left(>40^{\circ} \mathrm{C}\right)$ during the first week after challenge, with peaks on the second and third days at $41.2-41.4{ }^{\circ} \mathrm{C}$ in the vaccine and control groups, respectively. The temperature in both groups continued to fluctuate as the days passed, and by day seven postchallenge, the pigs in both groups returned to very similar temperatures below $40{ }^{\circ} \mathrm{C}$.

The pigs in both groups began with similar body weights, namely, $11.6 \pm 1.9 \mathrm{~kg}$ and $11.6 \pm 2.1 \mathrm{~kg}$ in the control and vaccine groups, respectively. Nonetheless, the pigs in the control group showed a slightly higher average daily weight gain (ADWG) than those in the vaccine group during the experiment. The control group pigs had an ADWG of $0.44 \pm 0.14 \mathrm{~kg}$ from the vaccination day to the challenge day and an ADWG of $0.51 \pm 0.22 \mathrm{~kg}$ from the challenge day to the necropsy day at the end of 
the experiment. In contrast, the vaccine group had an ADWG of $0.35 \pm 0.11 \mathrm{~kg}$ from the vaccination day to the challenge day and an ADWG of $0.37 \pm 0.17 \mathrm{~kg}$ from the challenge day to the necropsy day. However, the difference between the groups was not significant $(p>0.05)$.

\subsection{Frequency of Specific IFN- $\gamma$-Secreting $C D 4^{+}$Cells}

To determine the immunogenicity of the recombinant mouse $x$ pig chimeric antibody, the frequency of $\mathrm{CD} 4^{+} \mathrm{IFN} \gamma^{+}$cells was evaluated ex vivo in response to the peptides contained in the antigenized antibody. Figure 2A shows a representative flow cytometry analysis to determine the presence of $\mathrm{CD} 4^{+} \mathrm{IFN} \gamma^{+}$cells. The results show an overall low $\mathrm{CD} 4^{+}$IFN- $\gamma$-secreting cell response to the peptides and virus in both groups. Detectable frequencies of $\mathrm{CD} 4^{+} \mathrm{IFN} \gamma^{+}$cells in response to the Gp5-KK, GP-LC, and GP5-SL peptides were mainly observed in the control group, while no pigs in the vaccine group responded to these peptides (Figure 2B). Detectable frequencies of $\mathrm{CD} 4^{+} \mathrm{IFN} \gamma^{+}$cells in the vaccine group occurred mostly in response to M-AL, M-CS, Nsp2-SV, and Nsp-KR. With the exception of the peptide $\mathrm{M}-\mathrm{AL}$, the peptides produced a stronger response in the vaccine group than in the control group. Finally, only one pig in each group responded to the virus, albeit with differences in frequency. Nonetheless, there was no statistical significance between the groups for any of the stimuli.

(A)

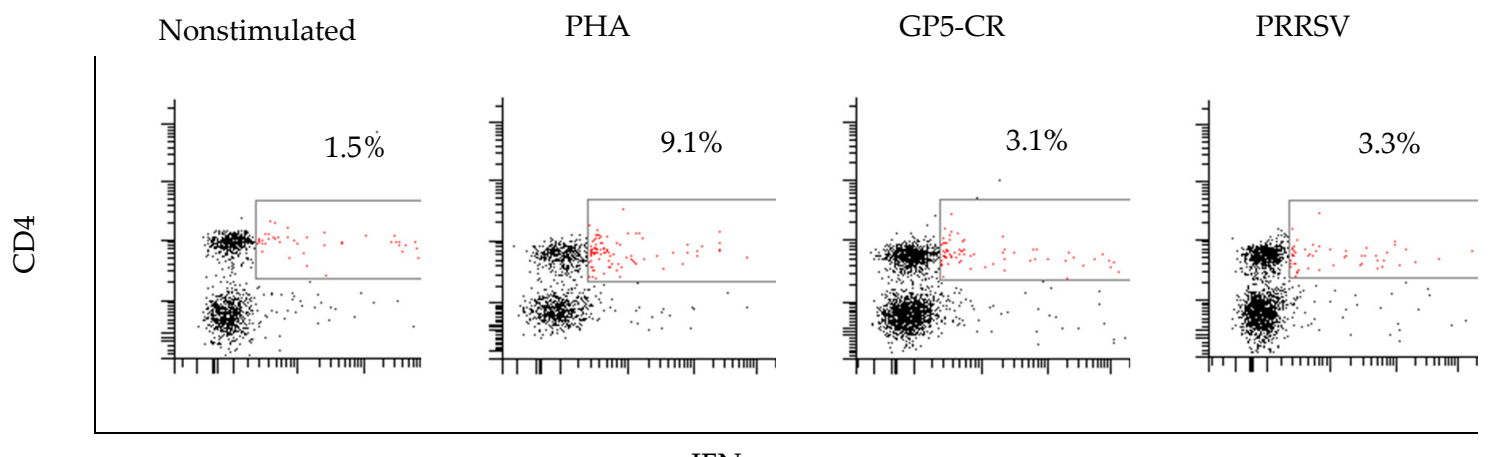

IFN- $\gamma$

(B)

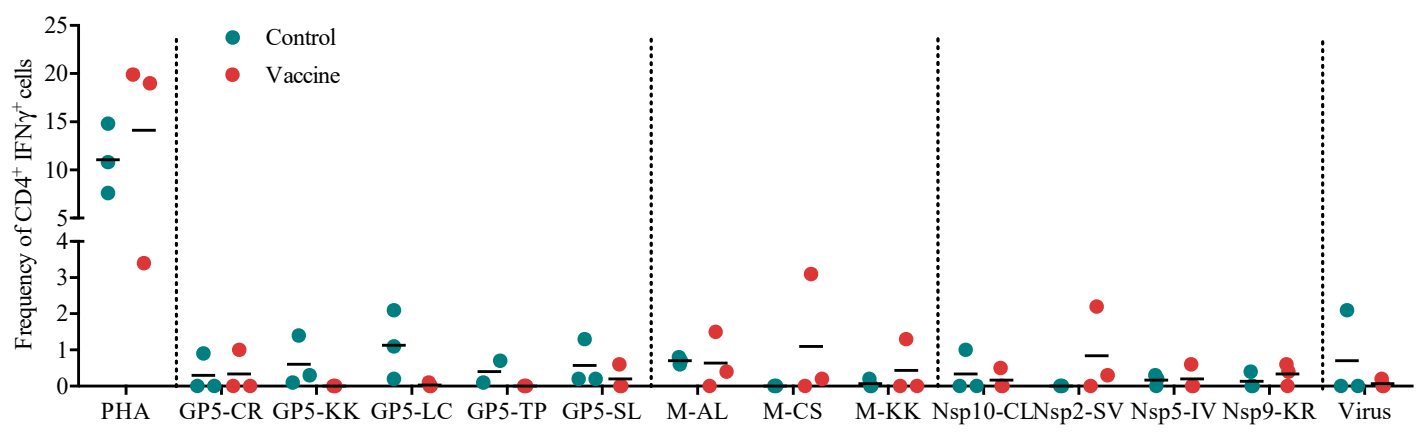

Figure 2. Analysis of $\mathrm{CD} 4{ }^{+} \mathrm{IFN}-\gamma$-secreting cells. (A) Representative experiment with PBMCs stimulated with individual porcine reproductive and respiratory syndrome virus (PRRSV) peptides, the whole virus, phytohaemagglutinin (PHA) (positive control) or medium along (unstimulated control). For extracellular labeling, an anti-CD4 antibody conjugated with fluorescein isothiocyanate (FITC) was used, and for intracellular staining, an anti-pig IFN- $\gamma$ antibody conjugated with phycoerythrin (PE) was used. The selected population corresponded to CD $4^{+}$IFN- $\gamma^{+}$cells. (B) Frequency of CD4 ${ }^{+}$ IFN- $\gamma$-secreting cells in immunized pigs. The results were obtained by subtracting the percentage of $\mathrm{CD} 4{ }^{+} \mathrm{IFN}-\gamma^{+}$cells in the unstimulated cell group from the percentage of double-positive cells in the experimental group. 


\subsection{Proliferation of PBMCs in Response to Individual Peptides or Virus}

The proliferative response of PBMCs to different stimuli is expressed as a cell percentage (Figure 3). The results showed that at least one pig in the vaccine group had the capacity to proliferate in response to all the peptides and the virus, which was not the case in the control group, where the proliferative response was almost null. All the pigs in the vaccine group responded to the GP5-LC, GP5-SL, $\mathrm{M}-\mathrm{AL}$, and M-KK peptides, albeit with differences in magnitude. For the peptides M-CS, Nsp10-CL, and Nsp9-KR and the virus, the vaccine group had two responding pigs, while the control group had a similar response to the M-CS peptide but no response to any of the Nsps peptides or the virus. However, there was no significant difference in the response to any of the stimuli between the groups.

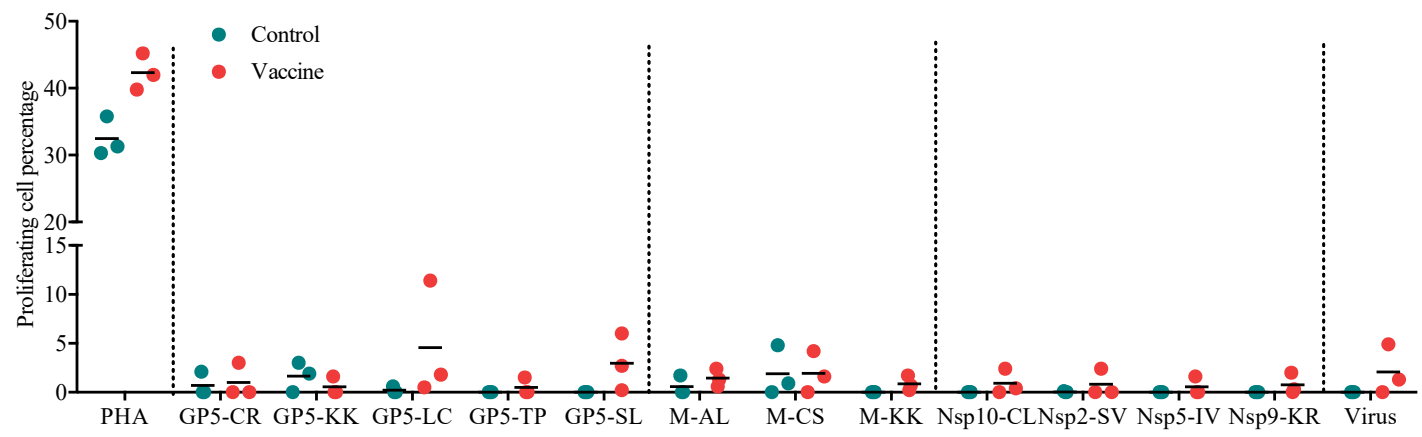

Figure 3. Proliferation of PBMCs from immunized pigs in response to structural and nonstructural peptides and PRRSV. The results were obtained by subtracting the percentage of proliferating cells observed with the unstimulated cells from the percentage observed with the stimulated cells.

\subsection{Anti-PRRSV Antibody Response}

We compared the antibody response four times, the beginning of the experiment (prime), the booster day, the challenge day, and three weeks postchallenge, by ELISA (Figure 4A). Overall, we found that the vaccine group had a higher antibody response to the virus PRRS than did the control group. Particularly, on the day of the booster immunization (Day 21), on the day of the challenge (Day 35), and at week three postchallenge (Day 56), the antibody levels were significantly greater in the vaccine group than in the control group $(p \leq 0.05)$. The ELISA (IDEXX) showed that, by week three postchallenge, all infected pigs had seroconverted and presented a strong positive status $(p \leq 0.001)$ (Figure 4B).

(A)

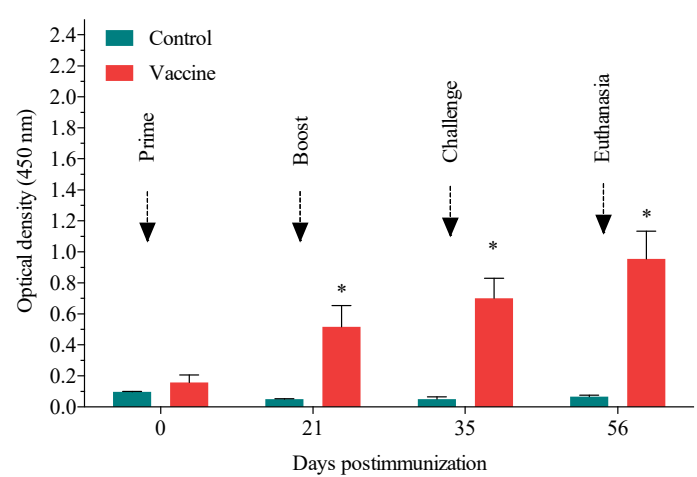

(B)

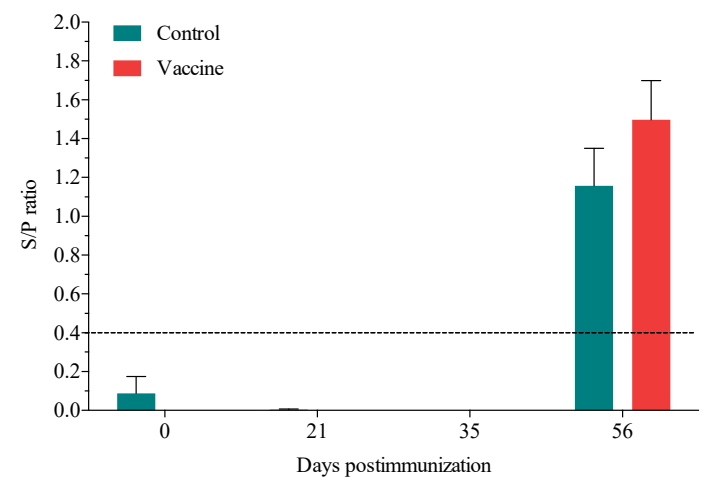

Figure 4. Antibody response to the anti-PRRSV antibody. (A) Evaluation of antibodies against the anti-PRRSV antibody at the beginning of the experiment (Day 0), at the time of the booster immunization (Day 21), at the time of the challenge (Day 35), and at the end of the experiment (Day 56) by ELISA. Gray bars represent the control group, and blue bars represent the vaccine group. Bars represent the mean \pm standard error (SE) of three animals. (B) Antibody response evaluated by a commercial kit from IDEXX to confirm seroconversion in the challenged pigs. 


\subsection{Viremia and the Viral Load in the Lungs and Tonsils}

To evaluate protection in the vaccinated pigs, viremia and viral loads were evaluated. Seven days after challenge, the control and vaccine groups were both viremic, and there was no significant difference between them (Figure 5A). The following week, decreased viremia was observed in both groups, and by three weeks postchallenge, only two pigs in each group had detectable viral levels. Likewise, the viral load in the lungs at the end of the study was not different between the control and vaccine groups, and one pig in each group was negative (Figure 5B). In contrast, the viral load in the tonsils showed that only one pig in the vaccine group was positive, and this pig had a lower viral load than the two positive pigs in the control group (Figure 5C).

(A)

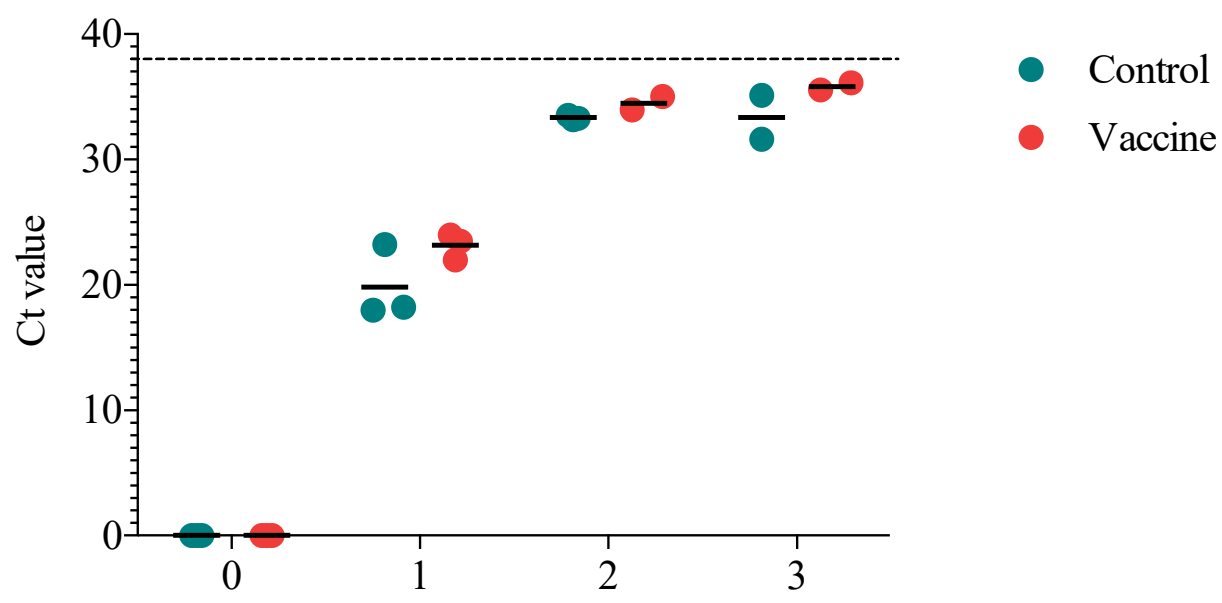

Weeks after challenge

(B)

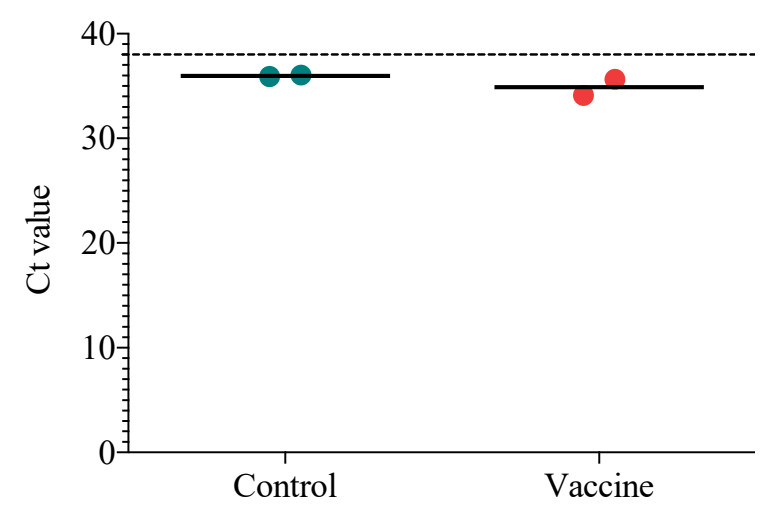

(C)

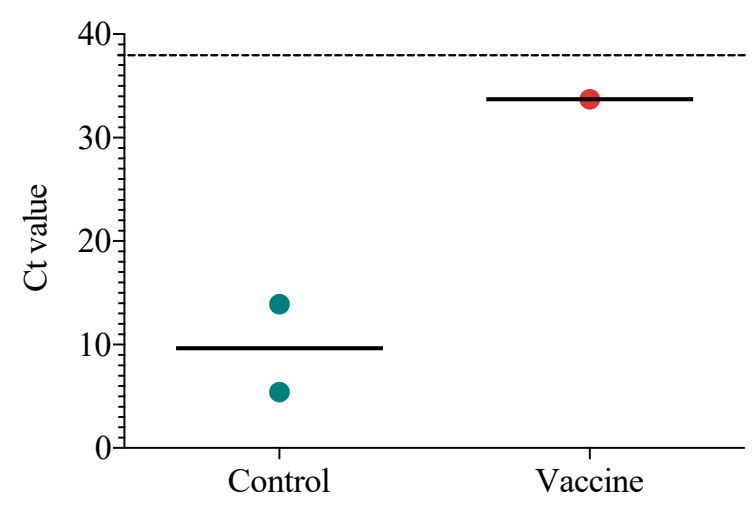

Figure 5. Viremia and the viral load in the lungs and tonsils of challenged pigs. (A) Viremia evaluated on the day of the challenge and every week thereafter until the end of the experiment (three weeks postchallenge). The viral load in the lungs (B) and tonsils (C) at the end of the experiment. The results are expressed as cycle threshold $(\mathrm{Ct})$ values, and the dotted line represents the cut-off for qPCR. Each point represents the $C t$ value of one pig.

\subsection{Microscopic Lung Lesion Evaluation}

We observed similar microscopic lesions indicative of interstitial pneumonia due to PRRSV infection in both groups (Figure 6). In the control group, only two pigs had lesions, one slight and the other moderate, while in the vaccine group, two pigs had moderate lesions. One pig in each group had no apparent pulmonary lesions. The differences between the groups were not statistically significant (Table 1). 


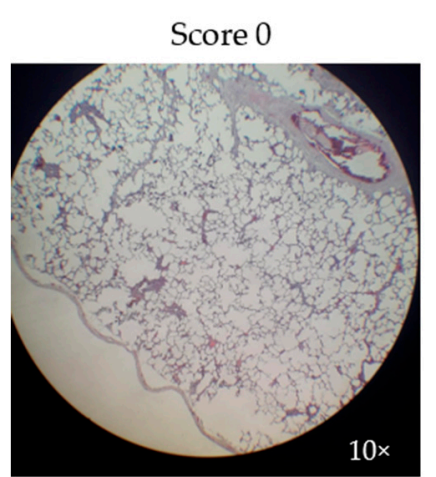

Score 2

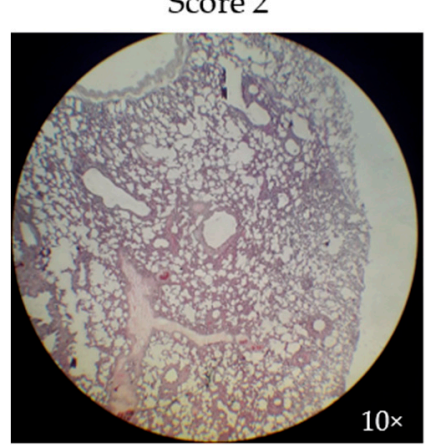

Score 1

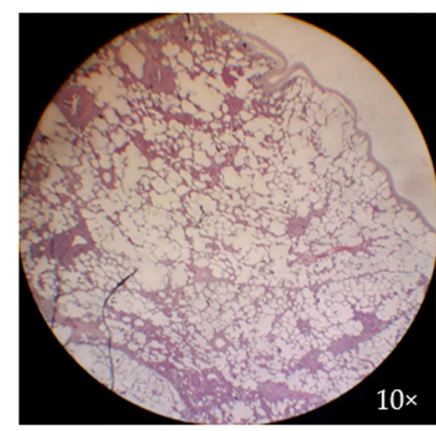

Score 3

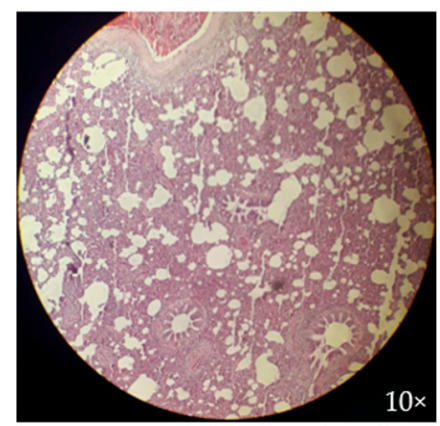

Figure 6. Microscopic lung lesion evaluation of immunized pigs at the end of the experiment. The scoring system utilized to evaluate the severity of the lung lesions found in pigs was as follows: 0—no significant lesions; 1 -mild significant lesions; 2-moderate significant lesions; and 3-severe significant lesions. Tissue samples were magnified at $10 \times$.

Table 1. Microscopic lung lesion scores for the groups.

\begin{tabular}{ccc}
\hline \multirow{2}{*}{ Microscopic Lung Lesions Score } & \multicolumn{2}{c}{ Number of Pigs with Each Score } \\
\cline { 2 - 3 } & Control Group & Vaccine Group \\
\hline 0 & $1 / 3$ & $1 / 3$ \\
1 & $1 / 3$ & $0 / 3$ \\
2 & $1 / 3$ & $2 / 3$ \\
3 & $0 / 3$ & $0 / 3$ \\
\hline
\end{tabular}

The utilized scoring system evaluated the severity of lung lesions in the following manner: 0-no significant lesions; 1-mild significant lesions; 2-moderate significant lesions; and 3-severe significant lesions (see Figure 3).

\section{Discussion}

Previous reports have demonstrated that antigen targeting to different DC receptors results in increased antibody production, cell activation, and cytokine secretion [20]; thus, antigen targeting using recombinant antibodies has been presented as a potential tool for effective vaccination in veterinary medicine [21]. The persistence of PRRSV in porcine farms over time continues to drive the constant development of vaccines to prevent infection outbreaks and maintain farms in a negative status to reduce the economic impact of PRRSV [22,23]. Overall, the improvement of current vaccination tools and the development of improved vaccination tools are much needed in porciculture around the world; thus, we are attempting to improve current results with an antigen targeting approach to control PRRSV infection. In the present work, we show that antigen targeting of structural and nonstructural peptides of PRRSV towards DEC205 ${ }^{+}$DCs using a recombinant chimeric mouse $x$ pig antibody is immunogenic but produces limited protective immunity in challenged pigs.

The cellular response was evaluated by measuring the frequency of specific $\mathrm{CD} 4^{+} \mathrm{IFN}-\gamma$-secreting cells and PBMC proliferation. Interestingly, the peptides that elicited a higher frequency of specific 
$\mathrm{CD} 4{ }^{+} \mathrm{IFN}-\gamma$-secreting cells in the vaccine group were part of the $\mathrm{M}$ protein (M-AL, M-CS, and M-KK), which has been previously identified as a potent inducer of IFN- $\gamma$ [16]; in contrast, the control group had a predominant response to peptides from GP5 (GP5-KK, GP5-LC, and GP5-TP), the most variable protein in the virus [16]. However, we did not observe a significant IFN- $\gamma$ response towards the nonstructural peptides, including those from Nsp10 and Nsp9, even though these proteins have been classified as strong IFN- $\gamma$ inducers [15]. These findings are in accord with prior reports from our research group $[13,24,25]$, which suggest that the induction of memory $\mathrm{T}$ cells against these antigens requires a large number of antigen exposures [24]. Our results are also in agreement with previous results showing that the use of DEC205 targeting of viral proteins (GP5, GP4, and GP3) produces a null $\mathrm{CD}^{+}{ }^{+}$cell response [8]. The use of DEC205 to target dendritic cells has been shown to induce strong IFN- $\gamma$ production in humans and mice $[8,16]$. Nevertheless, in our results, the response involving typical Th1 cytokines, such as IFN- $\gamma$, was poorly stimulated.

An in-house-created indirect ELISA evaluating the antibody response to the whole virus measured the humoral response to PRRSV. Interestingly, compared to the control group, the vaccine group presented enhanced production of antibodies against PRRS after the first immunization until the end of the experiment. The GP5 and M proteins are known to have B cell epitopes and thus enhance the humoral response [26]. Nonetheless, our results clearly showed an enhanced humoral response compared to the responses measured in other targeting studies where larger antigenic proteins were used [8,27], thus further indicating an improvement in the vaccination strategy used in this work. It is possible that the use of a recombinant chimeric mouse $x$ pig antibody via intradermal application can increase the immunogenicity of this useful strategy. Unfortunately, neutralizing antibodies were not evaluated in this study.

Regardless of the elevated level of anti-PRRSV antibodies detected, we did not observe a difference in viremia or the lung viral load between the vaccine and control groups. However, we found that, in the tonsils, the vaccine group contained two pigs that were negative for PRRSV, while the control group contained two pigs with a high viral load. Surprisingly, the tonsils are considered to be a site of PRRSV persistence, as are the lungs, although this persistence did not appear to occur in our study. Moreover, microscopic lung lesions did not show any significant differences between the groups, which both included pigs with mild to moderate lesions. Similar results for viremia, the lung viral load and microscopic lesions were observed in other studies where structural and nonstructural peptides were used $[8,16]$. In contrast to our findings, the results of Subramaniam et al. showed that antigen targeting of the structural peptides GP3, GP4, GP5, and M to DEC205 ${ }^{+} \mathrm{DC}$ s fails to induce a significantly enhanced humoral response or cellular response, as measured by IFN- $\gamma$-secreting cells, and has no effect on viremia, the lung viral load or microscopic lung lesions in immunized pigs [8]. The differences between that study and ours are most likely due to the selected immunogenic peptides, the use of a recombinant chimeric mouse $x$ pig antibody and the administration route used, as the intradermal approach is more suitable because of the prevalence of DCs is higher in the skin than in the muscle [28]. Moreover, the injection site for our antigenized rAb was near the submaxillary lymph nodes and tonsils, which have been shown to have a higher percentage of DEC205 ${ }^{+}$DCs than other secondary lymphoid organs, such as the spleen [29]. This increased percentage would mean greater exposure to the targeted cells and lymph node trafficking and could translate into a more efficient vaccine performance [30].

However, as evidenced by the results, not all the peptides selected in this study induced a strong immunogenic response. Replacing the less immunogenic peptides with others that are more reactive or simply repeating the more immunogenic peptides could augment the probability of immunogenic peptide presentation and induce a stronger response. In line with this supposition, since approximately $20 \%$ of the protein corresponds to the antigenized region, which means that each peptide accounts for $1.6 \%$ of the whole structure, a higher dose of the vaccine could be necessary to produce a greater response and generate superior protective immunity. Thus, higher doses and different antigens need to be evaluated to enhance the immunogenicity of this vaccine. Furthermore, the use of more 
potent adjuvants could also improve the effectiveness of the vaccine; while poly I:C is considered a potent adjuvant, polyinosinic-polycytidylic acid and poly-L-lysine double-stranded RN (poly ICLC), a derivate of poly-IC stabilized with poly-l-lysine and carboxymethylcellulose, has shown promising results in nonhuman primates [31,32].

\section{Conclusions}

In summary, the results show that antigen targeting of structural and nonstructural peptides of PRRSV towards DEC205 ${ }^{+}$DCs using a recombinant chimeric mouse $\mathrm{x}$ pig antibody exhibits immunogenicity but produces limited protective immunity in challenged pigs. It is important to note that inducing protective immunity against PRRSV is a substantial challenge. For this reason, several adjustments, including replacing the antigens that showed the lowest immunogenicity with others that are more immunogenic, could be made, and using a higher dose of the vaccine could definitely increase protection. However, it is important to mention that the immunogenicity observed with the use of the chimeric mouse $x$ pig anti-DEC205 antibody can be used in other infection models. Further studies are needed to probe the application of this novel strategy.

Author Contributions: The authors listed have made a substantial, direct, and intellectual contribution to the work and have approved this manuscript for publication. The individual contributions were as follows: conceptualization: J.H.; methodology: L.B.-C. and M.R.-S.; formal analysis: L.B.-C.; resources: J.H.; data curation: L.B.C. and M.R.-S.; writing—original draft preparation: L.B.-C.; writing—review and editing: J.H.; supervision: J.H.; project administration: J.H.; funding acquisition: J.H.

Funding: The present work was funded by CONACyT-PN 2015 project number 248922 and INFRA-2015-01-25482. L.B.C. is the recipient of a scholarship from CONACyT and is currently in the program of Doctorado en Ciencias of the Centro de Investigación en Alimentación y Desarrollo, A.C.

Acknowledgments: To Luis Andrey Gómez Vázquez for his technical support.

Conflicts of Interest: The authors declare that they have no conflicts of interest. The funders had no role in the design of the study; in the collection, analysis, or interpretation of the data; in the writing of the manuscript; or in the decision to publish the results.

\section{References}

1. Moyer, T.J.; Zmolek, A.C.; Irvine, D.J. Beyond antigens and adjuvants: Formulating future vaccines. J. Clin. Investig. 2016, 126, 799-808. [CrossRef] [PubMed]

2. Trumpfheller, C.; Longhi, M.P.; Caskey, M.; Idoyaga, J.; Bozzacco, L.; Keler, T.; Schlesinger, S.J.; Steinman, R.M. Dendritic cell-targeted protein vaccines: A novel approach to induce T-cell immunity. J. Intern. Med. 2012, 271, 183-192. [CrossRef] [PubMed]

3. Bonifaz, L.C.; Bonnyay, D.P.; Charalambous, A.; Darguste, D.I.; Fujii, S.-I.; Soares, H.; Brimnes, M.K.; Moltedo, B.; Moran, T.M.; Steinman, R.M. In vivo targeting of antigens to maturing dendritic cells via the DEC-205 receptor improves T cell vaccination. J. Exp. Med. 2004, 199, 815-824. [CrossRef] [PubMed]

4. Coconi-Linares, N.; Ortega-Dávila, E.; López-González, M.; García-Machorro, J.; García-Cordero, J.; Steinman, R.M.; Cedillo-Barrón, L.; Gómez-Lim, M.A. Targeting of envelope domain III protein of DENV type 2 to DEC-205 receptor elicits neutralizing antibodies in mice. Vaccine 2013, 31, 2366-2371. [CrossRef]

5. Birkholz, K.; Schwenkert, M.; Kellner, C.; Gross, S.; Fey, G.; Schuler-Thurner, B.; Schuler, G.; Schaft, N.; Dörrie, J. Targeting of DEC-205 on human dendritic cells results in efficient MHC class II-restricted antigen presentation. Blood 2010, 116, 2277-2285. [CrossRef]

6. Jauregui-Zuniga, D.; Pedraza-Escalona, M.; Espino-Solis, G.P.; Quintero-Hernandez, V.; Olvera-Rodriguez, A.; Diaz-Salinas, M.A.; Lopez, S.; Possani, L.D. Targeting antigens to Dec-205 on dendritic cells induces a higher immune response in chickens: Hemagglutinin of avian influenza virus example. Res. Vet. Sci. 2017, 111, 55-62. [CrossRef] [PubMed]

7. Njongmeta, L.M.; Bray, J.; Davies, C.J.; Davis, W.C.; Howard, C.J.; Hope, J.C.; Palmer, G.H.; Brown, W.C.; Mwangi, W. CD205 antigen targeting combined with dendritic cell recruitment factors and antigen-linked CD40L activation primes and expands significant antigen-specific antibody and $\mathrm{CD}^{+} \mathrm{T}$ cell responses following DNA vaccination of outbred animals. Vaccine 2012, 30, 1624-1635. [CrossRef] [PubMed] 
8. Subramaniam, S.; Piñeyro, P.; Derscheid, R.J.; Madson, D.M.; Magstadt, D.R.; Meng, X.-J. Dendritic cell-targeted porcine reproductive and respiratory syndrome virus (PRRSV) antigens adjuvanted with polyinosinic-polycytidylic acid (poly (I: C)) induced non-protective immune responses against heterologous type 2 PRRSV challenge in pigs. Vet. Immunol. Immunopathol. 2017, 190, 18-25. [CrossRef]

9. Jiang, W.; Jiang, P.; Li, Y.; Tang, J.; Wang, X.; Ma, S. Recombinant adenovirus expressing GP5 and M fusion proteins of porcine reproductive and respiratory syndrome virus induce both humoral and cell-mediated immune responses in mice. Vet. Immunol. Immunopathol. 2006, 113, 169-180. [CrossRef]

10. De Lima, M.; Pattnaik, A.K.; Flores, E.F.; Osorio, F.A. Serologic marker candidates identified among B-cell linear epitopes of Nsp2 and structural proteins of a North American strain of porcine reproductive and respiratory syndrome virus. Virology 2006, 353, 410-421. [CrossRef]

11. Oleksiewicz, M.; Bøtner, A.; Toft, P.; Normann, P.; Storgaard, T. Epitope mapping porcine reproductive and respiratory syndrome virus by phage display: The nsp2 fragment of the replicase polyprotein contains a cluster of B-cell epitopes. J. Virol. 2001, 75, 3277-3290. [CrossRef] [PubMed]

12. Meier, W.A.; Galeota, J.; Osorio, F.A.; Husmann, R.J.; Schnitzlein, W.M.; Zuckermann, F.A. Gradual development of the interferon- $\gamma$ response of swine to porcine reproductive and respiratory syndrome virus infection or vaccination. Virology 2003, 309, 18-31. [CrossRef]

13. Burgara-Estrella, A.; Diaz, I.; Rodriguez-Gomez, I.M.; Essler, S.E.; Hernandez, J.; Mateu, E. Predicted peptides from non-structural proteins of porcine reproductive and respiratory syndrome virus are able to induce IFN-gamma and IL-10. Viruses 2013, 5, 663-677. [CrossRef]

14. Mokhtar, H.; Eck, M.; Morgan, S.B.; Essler, S.E.; Frossard, J.-P.; Ruggli, N.; Graham, S.P. Proteome-wide screening of the European porcine reproductive and respiratory syndrome virus reveals a broad range of $\mathrm{T}$ cell antigen reactivity. Vaccine 2014, 32, 6828-6837. [CrossRef] [PubMed]

15. Parida, R.; Choi, I.-S.; Peterson, D.A.; Pattnaik, A.K.; Laegreid, W.; Zuckermann, F.A.; Osorio, F.A. Location of T-cell epitopes in nonstructural proteins 9 and 10 of type-II porcine reproductive and respiratory syndrome virus. Virus Res. 2012, 169, 13-21. [CrossRef] [PubMed]

16. Hernández, J.; Rascon-Castelo, E.; Bray, J.; Lokhandwala, S.; Mwangi, W. Immunogenicity of a recombinant adenovirus expressing porcine reproductive and respiratory syndrome virus polyepitopes. Vet. Microbiol. 2017, 212, 7-15. [CrossRef]

17. Flores-Mendoza, L.; Sotelo-Mundo, R.R.; Dawson, H.; Mwangi, W.; Hernández, J. Characterization of porcine CD205. Dev. Compar. Immunol. 2010, 34, 715-721. [CrossRef]

18. Silva-Campa, E.; Mata-Haro, V.; Mateu, E.; Hernández, J. Porcine reproductive and respiratory syndrome virus induces $\mathrm{CD}^{+} \mathrm{CD}^{+} \mathrm{CD}^{2} 5^{+} \mathrm{Foxp}^{+}$regulatory T cells (Tregs). Virology 2012, 430, 73-80. [CrossRef]

19. Robinson, S.R.; Rahe, M.C.; Gray, D.K.; Martins, K.V.; Murtaugh, M.P. Porcine reproductive and respiratory syndrome virus neutralizing antibodies provide in vivo cross-protection to PRRSV1 and PRRSV2 viral challenge. Virus Res. 2018, 248, 13-23. [CrossRef]

20. Chappell, C.P.; Giltiay, N.V.; Dresch, C.; Clark, E.A. Controlling immune responses by targeting antigens to dendritic cell subsets and B cells. Int. Immunol. 2014, 26, 3-11. [CrossRef]

21. Bustamante-Córdova, L.; Melgoza-González, E.A.; Hernández, J. Recombinant antibodies in veterinary medicine: An update. Front. Vet. Sci. 2018, 5, 175. [CrossRef] [PubMed]

22. Nathues, H.; Alarcon, P.; Rushton, J.; Jolie, R.; Fiebig, K.; Jimenez, M.; Geurts, V.; Nathues, C. Modelling the economic efficiency of using different strategies to control porcine reproductive \& respiratory syndrome at herd level. Prev. Vet. Med. 2018, 152, 89-102. [CrossRef]

23. Neumann, E.J.; Kliebenstein, J.B.; Johnson, C.D.; Mabry, J.W.; Bush, E.J.; Seitzinger, A.H.; Green, A.L.; Zimmerman, J.J. Assessment of the economic impact of porcine reproductive and respiratory syndrome on swine production in the United States. J. Am. Vet. Med. Assoc. 2005, 227, 385-392. [CrossRef] [PubMed]

24. Rascon-Castelo, E.; Burgara-Estrella, A.; Resendiz-Sandoval, M.; Hernandez-Lugo, A.; Hernandez, J. Immune Response of multiparous hyper-immunized sows against peptides from non-structural and structural proteins of PRRSV. Vaccines 2015, 3, 973-987. [CrossRef]

25. Rascon-Castelo, E.; Burgara-Estrella, A.; Mateu, E.; Hernandez, J. Immunological features of the non-structural proteins of porcine reproductive and respiratory syndrome virus. Viruses 2015, 7, 873-886. [CrossRef] [PubMed] 
26. Ostrowski, M.; Galeota, J.; Jar, A.; Platt, K.; Osorio, F.A.; Lopez, O. Identification of neutralizing and nonneutralizing epitopes in the porcine reproductive and respiratory syndrome virus GP5 ectodomain. J. Virol. 2002, 76, 4241-4250. [CrossRef]

27. Subramaniam, S.; Piñeyro, P.; Tian, D.; Overend, C.; Yugo, D.M.; Matzinger, S.R.; Rogers, A.J.; Haac, M.E.R.; Cao, Q.; Heffron, C.L. In vivo targeting of porcine reproductive and respiratory syndrome virus antigen through porcine DC-SIGN to dendritic cells elicits antigen-specific CD4T cell immunity in pigs. Vaccine 2014, 32, 6768-6775. [CrossRef]

28. Romani, N.; Flacher, V.; Tripp, C.H.; Sparber, F.; Ebner, S.; Stoitzner, P. Targeting skin dendritic cells to improve intradermal vaccination. Curr. Top. Microbiol. Immunol. 2012, 351, 113-138. [CrossRef]

29. Parra-Sanchez, H.; Puebla-Clark, L.; Resendiz, M.; Valenzuela, O.; Hernandez, J. Characterization and expression of DEC205 in the CDC1 and CDC2 subsets of porcine dendritic cells from spleen, tonsil, and submaxillary and mesenteric lymph nodes. Mol. Immunol. 2018, 96, 1-7. [CrossRef]

30. Tozuka, M.; Oka, T.; Jounai, N.; Egawa, G.; Ishii, K.J.; Kabashima, K.; Takeshita, F. Efficient antigen delivery to the draining lymph nodes is a key component in the immunogenic pathway of the intradermal vaccine. J. Dermatol. Sci. 2016, 82, 38-45. [CrossRef]

31. Tacken, P.J.; Figdor, C.G. Targeted antigen delivery and activation of dendritic cells in vivo: Steps towards cost effective vaccines. Semin. Immunol. 2011, 23, 12-20. [CrossRef] [PubMed]

32. Longhi, M.P.; Trumpfheller, C.; Idoyaga, J.; Caskey, M.; Matos, I.; Kluger, C.; Salazar, A.M.; Colonna, M.; Steinman, R.M. Dendritic cells require a systemic type I interferon response to mature and induce CD4 ${ }^{+}$Th1 immunity with poly IC as adjuvant. J. Exp. Med. 2009, 206, 1589-1602. [CrossRef] [PubMed]

(C) 2019 by the authors. Licensee MDPI, Basel, Switzerland. This article is an open access article distributed under the terms and conditions of the Creative Commons Attribution (CC BY) license (http://creativecommons.org/licenses/by/4.0/). 